\title{
The economic logic of prescribed burning law and regulation
}

\author{
JONATHAN YODER, DAVID M. ENGLE, MARCIA TILLEY, AND SAMUEL FUHLENDORF
}

Authors are Assistant Professor, Department of Agricultural and Resource Economics, Washington State University, Warth Distinguished Professor, Department of Plant and Soil Sciences, Professor, Department of Agricultural Economics, and Associate Professor, Department of Plant and Soil Sciences, Oklahoma State University, Stillwater, Okla. 74078.

\begin{abstract}
Prescribed burning has long been recognized as a useful tool in rangeland management, but with it comes the risk of fire and smoke damage to the property of others. All but 2 states have codified laws specifying criminal penalties or liability rules for prescribed burning, but the laws in a number of states have changed in recent years or are under review. We develop an economic model of the incentive and welfare effects of prescribed burning law and regulation in which the likelihood and extent of external damage can be reduced by precautionary effort on the part of both the burner and/or the victim. The model provides implications regarding the comparative advantages to the public of strict liability versus negligence rules. We conclude that the relative effectiveness of a liability rule depends in large part on the relative ability of burners and other landowners to mitigate the probability and extent of damage, as well as the legal costs associated with implementing a given liability rule.
\end{abstract}

Key Words: fire, natural resources policy, prescribed fire, rangeland fire, rangeland policy

Prescribed burning is an inherently risky rangeland management tool that can result in litigation and considerable liability exposure to the prescribed burner. Through much of the $20^{\text {th }}$ century, prescribed fire was resisted by policy makers and many natural resources managers because fire was considered a detriment to either ecosystem integrity or to ecosystem products (Pyne 1982, Biswell 1989). Even though fire is now widely viewed as a useful vegetation and fuels management tool (Bernardo et al. 1988, Svejcar 1989, Briggs and Knapp 1995, Zimmerman 1997, Babbitt 1995, Pattison 1998), the exposure to liability remains a primary impediment to increased use of prescribed burning in the United States. At the same time, state and federal programs (e.g., U.S.D.A. Environmental Quality Incentive Program) and policies encourage the use of prescribed burning. The Federal government recognized recently the use of prescribed fire as an integral element of wildland fire management, despite the explicit recogni-

Published with the support of the Oklahoma Agricultural Experiment Station through project OKL02431. We greatly appreciate the valuable suggestions of 2 anonymous referees.

Corresponding Author:Jonathan Yoder, Department of Agricultural and Resource Economics, P.O. Box 646210, Washington State University, Pullman, Wash. 99164-1173, Phone: (509) 335-8596, FAX: (509) 335-1173, email:

yoder@wsu.edu

Manuscript accepted 9 Jan. 2002.

\section{Resumen}

La quema prescrita ha sido reconocida mucho tiempo como una herramienta útil en el manejo de pastizales, pero con ella viene el riesgo de daño por humo y fuego a otras propiedades. Exceptuando 2 estados el resto ha establecido leyes especificando penalidades criminales o reglas por daños a terceros para la quema prescrita. Desarrollamos un modelo económico de los efectos del apoyo de gobierno e incentivos de la ley y regulación en quema prescrita, en el cual los daños a los vecinos y lo extenso del daño externo pueden ser reducidos por un esfuerzo precautorio tanto del que quema como de la victima. El modelo provee implicaciones relacionadas a las ventajas comparativas para el público estricto en daños a terceros versus reglas por negligencia. Concluimos que la efectividad relativa de una regla de daños a terceros depende en gran parte de la habilidad relativa de los que queman y de otros propietarios para mitigar la probabilidad y extensión del daño, así como de los costos legales asociados con la implementación de una regla de daños a terceros dada.

tion that it is among the most risky activities of federal land management agencies (U.S. Department of the Interior, U.S. Department of Agriculture 1995).

The relative incentives for individual prescribed burners (and society as a whole) versus the potential victims (individuals) of escaped fire differ widely because of the widely varying liability rules among states in the U.S. Virtually all states have codified civil or criminal statutory law for prescribed burning, but the structure of these laws varies substantially across states (Yoder et al. 2003). Only 4 states impose strict liability on prescribed burners. Under strict or unlimited liability, defendants are liable for the damage caused by an escaped prescribed fire even if there is no evidence of negligence on their part and regardless of the precautions taken to contain the fire. Most states with prescribed fire statutes impose negligence rules of some form on the prescribed burner, but again, these negligence rules vary substantially across states (Yoder et al. 2003). Not only do prescribed burning laws vary substantially across states, but these laws currently are in flux. The laws in most states have been revised since 1990, and a number of statutes are currently under review.

We build on a model adapted from the law and economics literature and developed in Yoder et al. 2003 to compare the capacity of the different liability rules to induce the economically appropriate level of precaution by prescribed burners and their neighbors. The intent of this paper is to provide a conceptual framework for assessing the economic efficiency and incentive effects 
of prescribed burning liability law so that rangeland resource managers can more knowledgeably articulate to policy makers the relative merits of alternative liability statutes.

\section{A Model of Liability for Prescribed Burning}

We will examine 2 neighboring property owners. One neighbor applies prescribed burning to his land, and a neighbor's property would suffer damage if the fire escaped onto his land. Suppose the probability of an escaped fire depends on precaution effort by the burner, and the extent of damage - given that a fire escapesdepends on precautionary effort taken by the victim. The following model is adapted from Brown (1973) and developed for this scenario by Yoder et al (2003).

First, consider the efficient (wealthmaximizing) levels of precaution; we will then examine the effectiveness of various liability rules for inducing this allocation. The total net value of a prescribed burn, $P$, is the value of the benefits from the burn minus the precaution costs and expected value of damage incurred by the burner and victim:

$$
\Pi=\mathrm{R}-\mathrm{D}(\mathrm{V}) \cdot \mathrm{P}(\mathrm{B})-\mathrm{W}^{\mathrm{v}} \mathrm{V}-\mathrm{W}^{\mathrm{b}} \mathrm{B}
$$

where

- $\mathrm{R}>0 \equiv$ the value of the burn to the burner (including society in general),

- $\mathrm{D}(\mathrm{V}) \equiv$ damage to the victim if fire escapes (potential damage),

- $\mathrm{P}(\mathrm{B}) \in(0,1) \equiv$ probability of an escape that results in damage,

- $\mathrm{V} \equiv$ the level of precaution invested by the victim,

- $B \equiv$ the level of precaution invested by the burner.

- $\mathrm{W}^{\mathrm{v}}$ and $\mathrm{W}^{\mathrm{b}} \equiv$ Cost of a unit of precaution for the victim and burner, respectively.

A central component of the analysis that follows is "expected damage," defined here as the statistical expectation of damage: $P(B) \cdot D(V)$. Notice that if either the probability of damage increases or potential damage increases, then expected damage increases. Examples of $\mathrm{V}$ (precaution by the victim) include the use of fire resistant construction materials in buildings and fuel reduction around structures (e.g., defensible space). Examples of B (precaution by the burner) include fire planning, constructing fuel breaks, notifying neighbors and fire officials, and utilizing sufficient manpower. Burning under narrow fire prescriptions, such as highly restrictive windows of air temperature and relative humidity, is an important factor that also can be considered a costly precaution by the burner (Roberts et al. 1999).

The economically efficient levels of precaution invested by the burner (B) and the victim (V) are those that maximize $\Pi$, the total net expected value of a burn. Assuming that the probability of an escape $(\mathrm{P}(\mathrm{B}))$ and damage to the victim $(\mathrm{D}(\mathrm{V}))$ decline at a diminishing rate with increases in precaution by the burner and victim (B and $\mathrm{V}$ ) respectively, the model provides a number of implications regarding the optimal precaution of the burner and the victim. Economic efficiency requires that both the burner and the victim take precautions to reduce potential damage except in special cases. First, if precaution by either the burner or the victim (B or V, respectively) is very costly or ineffective at reducing either the risk of escape $(\mathrm{P}(\mathrm{B}))$ or damage to the victim $(\mathrm{D}(\mathrm{V}))$, then it may be optimal for one, the other, or even both parties to expend no precautionary effort even when the use of prescribed fire is beneficial to the burner or to society in general (i.e. $\Pi(B=0, V=0)>0$ ). Second, if the probability of escape that leads to damage is very low for optimal levels of $\mathbf{B}$ (precaution by the burner), then it may be optimal for the victim to expend no precautionary effort. Similarly, if potential damage is very low for even low levels of $\mathrm{V}$ (precaution by the victim), then it may be optimal for the burner to take no precautionary effort (see Yoder et al. (2003) for mathematical justification of these results).
This model provides a framework for understanding how different liability rules influence incentives for prescribed burners to practice precaution and for potential victims to mitigate potential damage. Strict liability will be considered first, followed by an analysis of negligence rules.

\section{Strict liability}

Consider 2 scenarios: (1) the burner is not liable for (not required to pay for) damage suffered by the victim, and (2) the burner is liable for damage suffered by the victim.

Scenario (1) represents the case where no restrictions or responsibilities were placed on burners with regard to damage and burning. The victim bears all of the damage costs from an escaped fire, and will therefore exert the economically efficient level of precaution. On the other hand, the burner bears none of the damage costs if a fire escapes, and will therefore exert no effort to reduce the likelihood of escape. If the burner has cost-effective means of reducing the probability of escape, this level of precaution $(B=0)$ is inefficiently low ("cost-effective" means here that benefits exceed the cost for some level of precaution). Therefore, the probability of escape will be inefficiently high and expected damage from prescribed fire will be inefficiently high.

In scenario (2), The burner bears all the damage costs of an escaped fire in addition to his own precaution costs, and will therefore exert the efficient level of pre-

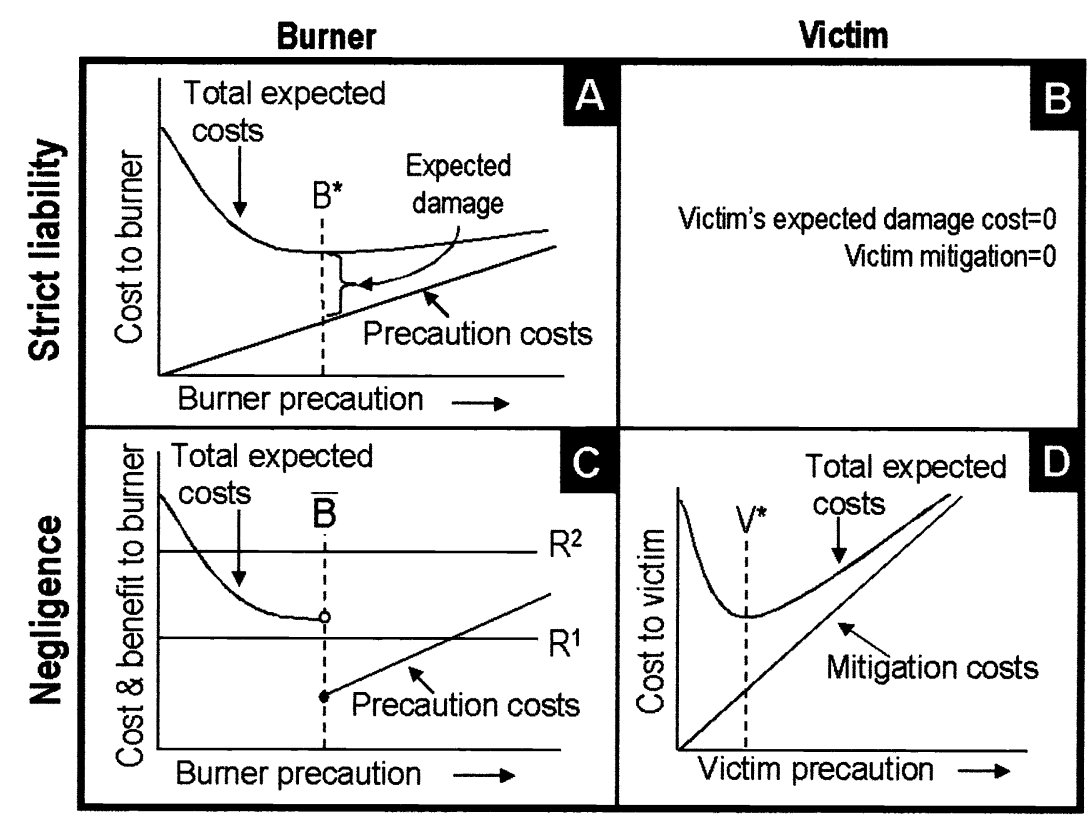

Fig. 1. Benefits and costs for the burner (left) and victim (right) under strict liability (top) and negligence (bottom). 
caution for any given level of victim precaution. The top row of Figure 1 shows benefits and costs for the burner (left) and victim (right) under strict liability. The burner bears precautionary costs and expects to pay for damage regardless of his precaution level. He therefore expends precautionary effort $\mathrm{B}^{*}$, which minimizes total expected costs-the sum of expected damage and precaution costs (panel A). The burner will choose to burn only if total expected costs at $\mathrm{B}^{*}$ are lower than the benefits (benefits are not shown in panel A). There is one crucial weakness of a strict liability rule such as this: the victim bears none of the damage costs of an escaped fire, and therefore has no incentive to exert effort to reduce potential damage to his property (panel B). If the victim has cost-effective means of reducing the extent of potential damage, this level of precaution $(\mathrm{V}=0)$ is inefficiently low. Therefore, expected damage, $\mathrm{P}(\mathrm{B}) \cdot \mathrm{D}(\mathrm{V})$, will be inefficiently high for any level of $B$. This was the case scenario (1) as well. This time, however, it is because potential damage to the victim's property, $\mathrm{D}(\mathrm{V})$, is too high rather than $\mathrm{P}(\mathrm{B})$ being too high. This discussion highlights 2 implications of the model.

Implication 1. Strict burner liability is more appropriate when the burner has cost-effective means to reduce expected damage but the victim has no control over potential damage.

Implication 1 suggests that when prescribed fire is, for any reason, uncommon in the vicinity, it makes less economic sense for potential victims to expend effort to prepare for it, and therefore efficiency losses from imposing strict liability on the burner are low. Strict burner liability is more likely to be more appropriate when and where the expected net social benefits of burning tend to be very low or negative and burning is an uncommon activity. Exceedingly costly precaution technologies available to the victim have the same result. If victims can not mitigate potential damage in an economical way, then strict liability results in no efficiency losses. Nonetheless, in fire-prone environments, inadequate precaution by the victim can result in great damage to the victim when wildfire occurs.

Implication 2. Strict victim liability is more appropriate when the victim has cost-effective means to reduce expected damage but the burner has no control over the probability of escape.

Implication 2 simply flips Implication 1 on its head. This result provides an illustration of one of the central arguments of
Coase (1960) in his seminal paper "The Problem of Social Cost." That is, in our use of the label "victim" and "burner," the distinction between victim and culprit turns on the ability to reduce expected damage, and is but a matter of degree. It would not be unusual for a burner to suffer significant financial loss should his fire escape even if prescribed burning provides value to society in general (e.g., fuel reduction, wildlife habitat enhancement, increased water yield, etc.). Using fireresistant construction as well as fuels reduction around homes are examples of victim actions that can reduce expected damage from escaped fire. Indeed, the increase recently in voluntary (e.g., Firewise, the national wildland/urban interface program) and mandated (e.g., Florida's fuel reduction statute) programs is indicative of the view that victims possess the ability to reduce expected damage from wildfire regardless of the fire's cause.

\section{Negligence}

With strict burner liability, the burner expects to bear both the costs of precaution and the value of damage to the victim. Now consider a negligence rule such that the burner is not liable for damage if precaution by the burner is greater than or equal to some negligence standard, $\overline{\mathrm{B}}$. If the burner satisfies the negligence standard $(B \geq \bar{B})$, he will accrue only his costs of precaution even if the fire were to escape and cause damage.

The second row of Figure 1 illustrates a negligence rule. In panel $\mathrm{C}$, the standard, $\overline{\mathrm{B}}$, is set to minimize the total expected cost of the prescribed burn, which is the economically efficient negligence standard (that is, $\overline{\mathrm{B}}$ in panel $\mathrm{C}$ is equal to $\mathrm{B}^{*}$ in panel A). The burner minimizes his costs by exactly satisfying the negligence standard; anything less and he will be found liable, but the burner does not benefit from exerting effort beyond that point. The victim then faces some probability of damage costs and therefore exerts precaution effort $\mathrm{V}^{*}$ (panel D). $\mathrm{R}^{2}$ and $\mathrm{R}^{1}$ in panel $\mathrm{C}$ represent different levels of benefit to the burner. If $\mathrm{R}=\mathrm{R}^{2}$ it is economically efficient to burn and the burner will do so. If $R=R^{1}$ total expected costs are greater than the benefits, but the burner will perform the burn because he does not expect to bear damage costs.

Given that the burner satisfies the negligence standard, the liability will fall on the victim; thus there is a discontinuity in the burner's cost function at $\bar{B}$. Assuming complete information, the victim knows that the burner has an incentive to satisfy the negligence standard, and therefore expects to bear the costs of any damage resulting from an escaped fire. This therefore induces the victim to exert the optimal level of care as well (Fig. 1, panel D).

An important characteristic of a negligence rule is that the burner will choose to apply precautionary effort at exactly $\bar{B}$ (Fig. 1, panel $\mathrm{C}$ shows that the level of precaution that minimizes total expected costs borne by the burner is exactly at $\overline{\mathrm{B}}$ ). If the negligence standard is not set at the efficient level of precaution $\left(\bar{B} \neq B^{*}\right.$, where total expected social costs are at their minimum as in Fig. 1 panel A), it will induce the burner to choose the wrong level of precaution. Accuracy of the negligence standard is therefore crucial to the success of a negligence rule as a means to induce efficient precaution.

Implication 3. A negligence rule is likely to be superior to strict liability when both burner and victim can substantially affect the value of expected damage.

It is possible to set a negligence rule so high that it effectively becomes a strict liability rule. Specifically, if the precautionary costs of reaching $\mathrm{B}$ are higher than the expected damage given no precautionary effort, then it would make sense economically for the burner to disregard the negligence standard and simply act as if he faces strict liability. Furthermore, given that the victim is aware of this incentive, the victim will expend no precautionary effort, and the result of an exceedingly high negligence standard is identical to strict liability in terms of both party's precautionary effort.

\section{To burn or not to burn}

The results above relate to the allocation of effort given that a prescribed fire is set by the burner. Rules that result in damage being borne by the burner and rules that result in damage being borne by the victim may affect the burner's decision to perform a prescribed fire.

Under a negligence rule, a burner may decide to burn even if total costs outweigh benefits. Figure 1 panel $\mathrm{C}$ suggests that a negligence rule may result in too many prescribed fires. $R^{2}$ represents a level of benefit that, at $\bar{B}$, covers both the costs of precaution and expected damage. From an efficiency perspective a prescribed burn should be conducted in this case. In contrast, $\mathrm{R}^{1}$ at $\overline{\mathrm{B}}$ covers the costs of precaution borne by the burner in order to satisfy the negligence rule, so the burn will be conducted. However, because total expected costs (i.e., precaution costs + expected 
damage) are larger than $R^{1}$ at $\bar{B}$, efficiency dictates that the burn should not be conducted. Thus, a burn will be conducted when it is inefficient to do so if the benefits to the burner lie between the costs of the optimal level of precaution $\left(\mathrm{W}^{\mathrm{b}} \mathrm{B}^{*}\right)$ and the total expected costs $\left(\mathrm{P}(\mathrm{B}) \mathrm{D}(\mathrm{V})+\mathrm{W}^{\mathrm{b}} \mathrm{B}^{*}\right)$. For any given distribution of $R$, this is more likely if the net benefits to the burner are positive but small, and when expected damage is large relative to the precaution costs. Indeed, benefits from a single prescribed burn on rangelands are often small relative to the risk to others (or at least not easily quantified).

In contrast, strict liability requires the burner to pay for damage in every case, and therefore is induced to provide efficient precautionary effort and start fires only when the total expected costs are outweighed by the benefits for any given level of precaution by the victim. The victim, on the other hand, has no incentive to expend precautionary effort. If $\mathrm{R}$ (the gross value of benefits) falls above the minimum total expected costs given efficient levels of precaution by the burner and victim, but below the minimum total expected costs given no victim effort $(\mathrm{V}=$ 0 ), the burn will not be performed even though it would be efficient to do so given efficient precaution by the victim. This case is shown in Figure 2 with $R=R^{3}$. As shown in the figure, under strict liability, $\mathrm{V}=0$. Total expected damage, and total expected costs (TC) for the burner are therefore higher for any level of $B$ than the efficient level resulting from $\mathrm{V}=\mathrm{V}^{*}$. If the benefits of the burn fall between the minima of these 2 cost curves (e.g., R3), a fire will not be set even though it would be set if the victim were performing precautionary effort. It follows from this discus- sion that if the net benefits of prescribed burning tend to be small, as is often the case on rangelands, a strict liability rule will tend to result in too few prescribed burns if the victim could (but does not) mitigate potential damage to his property.

The previous 2 paragraphs suggest the following implication about the relative efficiency of strict liability versus negligence based on the size of the benefits from prescribed fire:

Implication 4. A negligence rule is likely to be superior to strict liability when the expected net benefits of a prescribed burn (including expected damage) tend to be high.

\section{The usefulness of prior regulation and value-based rules}

At least 2 approaches might be used to address the incentive (discussed above) to conduct too many burns under a negligence standard. The first approach is to add a second type of negligence rule. Recall that the negligence rule discussed previously imposes a standard on the amount of precaution, $\mathrm{B}$, given that a fire is performed, and that this standard is in principle chosen based on the costs and benefits of precautionary effort. For purposes of comparison, call this an "inputbased" negligence standard; it imposes no restriction or requirement on whether a fire should be performed in the first place. A second negligence rule could be based on the total net expected social value of conducting a burn. Call this a "valuebased" negligence rule. It requires a burner to be found negligent if he conducts a burn when the expected total net benefits (including expected damage) are negative (Feldman and Frost 1998). Whereas an

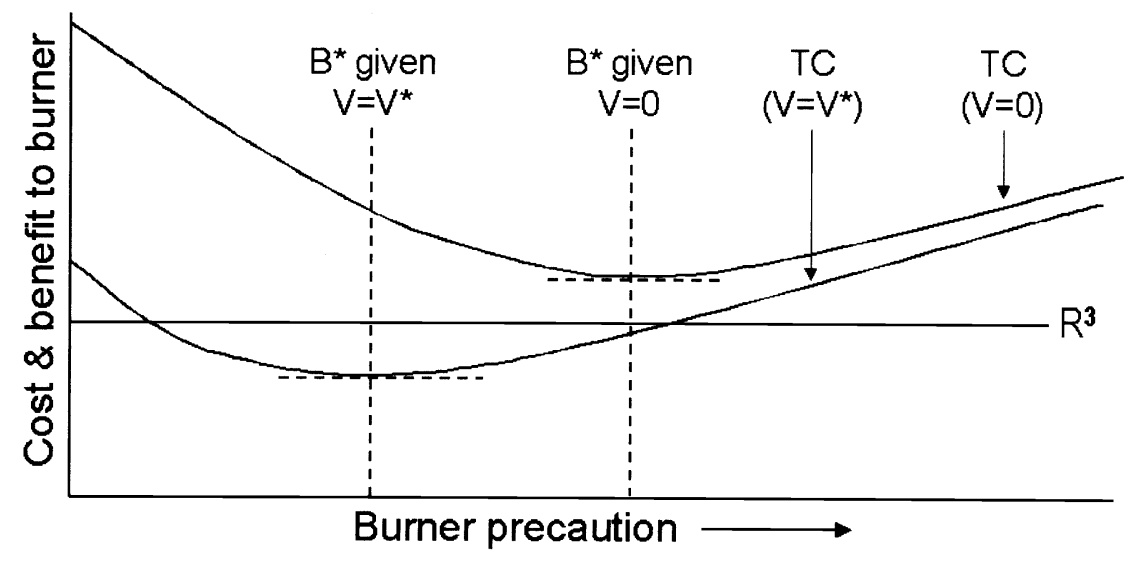

Fig. 2. The reduced incentive for victim precaution may lead to higher potential damage, more precaution by the burner, and fewer burns than is economically efficient. TC represents total costs and $\mathbf{R}^{3}$ represents benefits. input-based negligence rule cannot ensure that burns will not be performed too often, a rule based on the value of the burn cannot induce efficient precautionary effort. The 2 standards must be used together to address both problems. However, in order to implement a value-based standard, the court needs information about the benefits of a fire, as well as information about expected damage and the costs of precaution. To implement an input based rule, only information about damage and precaution costs are needed.

The second approach is to reinforce the input-based negligence rule with prior regulation such as requiring burners to acquire a permit before burning. Presumably, this permit would only be issued if the expected social net benefits of the burn are positive. Acquisition of these permits may also be contingent on evidence of some level of preparation such as a written prescribed burn plan. Permitting also may be used as explicit elements of a negligence standard if litigation ensues, thereby facilitating pretrial settlement and minimizing court costs. Thus, a permit system acts as a check on the problem inherent in negligence rules, that burners may tend to use prescribed burning too often.

Implication 5. Input-based negligence standards may be complemented by value-based negligence rules or a priori regulation.

For prescribed burns on rangeland, benefits to a larger group of society must be demonstrated, because benefits to a single land owner, manager, or for a single rangeland use often will be insufficient to justify a negligence rule over strict liability. Value-based negligence rules could provide a decided advantage to inputbased negligence rules over the long term by focusing public attention on benefits as well as requiring burners to justify burns. As with many environmental regulations, valuing the benefits of prescribed burns is often a subjective process. Valuing the benefits of a prescribed burn that enhances non-game habitat, for example, remains a challenge even to theoreticians (Tietenberg 2000).

\section{The importance of Information and transaction costs for liability rules}

The costs of gathering information and the effects of inconsistent or inaccurate negligence standards play a role in the relative effectiveness of a strict liability rule versus a negligence rule because enforcement of the 2 rules requires different information (Cooter 1991). A negligence rule 
requires information on the extent of damage only after the burner is found negligent by the court. In contrast, a strict liability rule requires information about the value of damage in order to settle every litigation event. If damage is not easily or credibly monetized, then a strict liability rule is at a comparative disadvantage for 2 reasons. First, over the course of numerous litigation events, the cumulative costs of generating damage estimates will be higher than with a negligence rule in which damage estimates are only required after a finding of negligence. Second, the outcome of litigation events may be different in a setting of imperfect information as compared to a setting with perfect damage information, leading the burner or victim to alter their patterns of care if the accuracy and precision of damage estimates is questionable.

The difference between smoke damage and physical fire damage provides an example. The extent of suffering by smoke inhalation from smoke exposure is likely to be more difficult to credibly verify than fire damage to a home. If victims tend to be able to extract excessive compensation, burners will be "too careful" from an efficiency perspective. As Cooter (1991) notes, this type of error will have more pronounced effects on the level of care under a strict liability rule because the effects will be felt every time litigation is brought, whereas under a negligence rule misspecified damages only matter when the burner is found negligent.

Perfectly specified negligence standards lead to efficient effort for any prescribed fire, but misspecified negligence standards will result in inefficient precaution by both parties. Consider Figure 1 again. Because the burner minimizes his expected costs at exactly $\bar{B}$ (or $B=0$ if $\bar{B}$ is set extremely high), the burner's behavior will be highly responsive to a consistently misspecified negligence rule. On the other hand, if the legal standard is vague and applied inconsistently by the courts, a negligence rule is likely to induce either too much or too little precautionary effort on the part of the burner even if the standard is on average applied correctly (Kolstad et al. 1990, Cooter and Ulen 1988). Both imprecise and inaccurate negligence rules reduce the benefits of negligence standards relative to strict liability, and both imprecision and inaccuracy follow from imperfect information about the cost and damage functions in a given case of prescribed burning.

If a negligence rule is imposed, information deficiencies also will shape the structure of a negligence rule. A statutory negli- gence rule may be vague, such as "a landowner is not liable for damage caused by a prescribed fire unless the landowner failed to exercise due care." This rule relegates the definition of "due care" to the courts. It may be associated with substantial a priori uncertainty as to the actual standard that will be imposed by the court. On the other hand, it allows a court to adjust to event-specific variation in the productivity and costs of precaution on a case-by-case basis. When the efficient precaution level is relatively invariant across events, a clear statutory standard may reduce litigation costs in terms of case-specific misspecification. This characterization of statutory ambiguity relates closely to the problem of incomplete contracts, which are those contracts for which all details cannot possibly be specified. Incomplete contracts are applicable to prescribed burning because specifying appropriate weather conditions inclusive of every potential prescribed burning objective and every rangeland setting is impossible. Three implications follow from this discussion.

Implication 6. A negligence rule is superior to a strict liability rule when damage $\mathrm{D}(\mathrm{V})$ is difficult to measure.

Implication 7. Statutory negligence standards should be precisely specified when precaution productivity and costs are relatively invariant (at the margin) across events.

Implication 6 applies to most rangeland burning for many reasons. Damage to rangeland properties is difficult and costly to assess and often subjectively determined. Moreover, rules-of-thumb that have been used to reduce costs of assessment are likely fraught with error (e.g., Engle and Bidwell 2001). Implication 7 suggests that for the sake of tractability, statutory negligence rules cannot cover all possible scenarios, and policy makers inevitably must search for the optimal mix of specific negligence standards (e.g. neighbor notification requirements) and ambiguous standards ("burners must exert due care").

The next section examines current prescribed fire law in the United States in the context of the model. However, one point about the applicability to the incentives of public land managers is worth noting. Prescribed fire use on many public lands has been increasing in the last decade, and the May 2000, Los Alamos fire in New Mexico is a well-known illustration of the grave consequences of the issue discussed here. It was started as a prescribed fire by the National Parks Service and resulted in approximately 24.5 million dollars in con- trol costs, damage, and rehabilitation costs (Interagency Burned Area Emergency Rehabilitation Team 2000).

Federal agencies are liable under state common law and state statutory law in basically the same way that private citizens are, but agency personnel are not held personally liable as are private citizens, except for violation of the constitution (Chalifour 1999). As a result, there is a disconnect between federal agency personnel and liability in terms of burner incentives. They may bear costs of negligence in the use of prescribed fire, but these costs will not be directly tied to the value of damage associated with their negligence. Rather, the costs they face are tied to agency-imposed penalties such as employment termination or other punitive agency responses. Furthermore, unlike a private landowner performing prescribed burning, agency personnel do not directly gain from the benefits of prescribed burning, because they do not own and have rights to utilize and gain from the land and its attributes to the extent a landowner does. Because of these disconnects between the agency personnel and the costs and benefits of burning, the model as developed here does not strictly apply, except to the extent that the costs and benefits of burning are felt by the decisionmakers through agency rules and incentive structures.

\section{Application to Current Statutory Law}

\section{Strict liability versus negligence rules}

Our model implies that strict liability is likely to induce efficient precaution if burners have most or complete control over the likelihood of damage due to prescribed fire, and it is not cost-effective for potential victims to reduce potential property damage from fires (implication 1). In the U.S., 22 states explicitly impose negligence rules and only 4 impose strict liability on burners (Yoder et al. 2003). This suggests policymakers recognize that potential victims generally have some control over the extent of damage that might be sustained as a result of prescribed burning.

Two specific elements common to a number of negligence standards also support this conclusion. First, some states have a 2-part negligence standard: (a) the burner must notify all adjacent landowners of his intentions, and (b), the burner must use all due caution to prevent the fire from escaping the property. The first element is 
very specific, and (at least in principle) easily verifiable. The second element leaves the definition of "due caution" for the court to define on a case-by-case basis. The point is that if neighbors have no means to mitigate potential damage, there would be no apparent motivation for the notification requirement.

Second, states can have a contributory negligence element in their statute. No rangeland state has such an element in their statutes (only Connecticut and Illinois have such). The statute has merit in that if victims do not expend reasonable effort to mitigate potential damage to their own property, the prescribed burner from whose land the fire originated will not be held liable. This contributory negligence rule recognizes a precautionary role for potential victims. The model suggests that strict liability provides little incentive for potential victims to exercise precautionary effort. Given that potential victims of escaped fire have an ability to mitigate damage, these specific requirements of notification and contributory negligence are consistent with the finding that most states with prescribed fire statutes rely on negligence rules rather than strict liability (Yoder et al. 2003).

Four states, including 2 rangeland states (North Dakota and Oklahoma), impose strict liability on the burner. Oklahoma's liability law was enacted in 1890 (prior to statehood) and last revised in 2001. North Dakota's was enacted in 1877 (last revised in 1943). The other 2 states, New Hampshire and Connecticut, are in the northern eastern seaboard states, where prescribed burning is relatively uncommon (implying a relatively low net value). This distribution of strict liability rules is consistent with our model (implication 4) in that states with strict liability rules tend to be in states where the net benefits of burning tend to be relatively low.

\section{Specificity of negligence rules}

Statutory rules relating to prescribed fire often contain an ambiguous statement requiring "due care", as well as more specific rules that are necessary (but not sufficient) to satisfy due care. The economic logic behind one common specific rule, the requirement to notify neighbors, is as follows. If landowners expect to be notified of their neighbor's intentions of prescribed burning, they need only be on alert for an escaped prescribed fire when such a fire is planned (and reported). This undoubtedly lowers their overall precaution costs, because time-sensitive precautionary effort (clearing dry vegetation near a house that might contribute to the extent of damage, for example) may then be performed only when the potential for an escaped prescribed fire exists, and need not be applied at other times. Furthermore, the cost to a burner of notifying adjacent landowners is likely to be relatively low. As a result, notification of neighbors will reduce the overall expected costs of a prescribed burn. Of course, the threat of wildfire still exists, but this probability is separate from that of prescribed burns from neighbors. It should be noted that not all precautionary effort need be time-specific. For example, using fire-resistant building materials does not necessarily require timely notification.

It would also be possible for a notification requirement to extend beyond adjacent landowners. However, notifying nearby landowners is not costless, and the potential gains from prior notification are likely to be lower because landowners further away will most likely have more time to react to the news of an escaped fire. Also, the probability of a fire crossing an adjacent landholding and onto landholdings further away are lower, so the expected costs to distant landowners are lower. Thus, the expected net benefits from a notification requirement for distant landholdings is not as compelling. Indeed, no landowner notification requirements extend to non-adjacent landowners. Notification requirements to non-adjacent landowners could be justified in some situations. For example, in some states small land holdings are common and fire spread is sufficiently rapid that non-adjacent landowners might not have time to react.

In some states, a burner must notify a related regulatory agency before burning in order to escape potential criminal penalties or civil liability. Colorado statutes state that a person who starts a fire is not liable for the expenses of extinguishing an escaped fire if he notifies the sheriff of the time and place of the burn. To the extent that prior notification reduces the cost or increases the effectiveness of public firefighting effort, this negligence requirement does so at only a small cost to the burner (a telephone call, perhaps).

Another common specific requirement among state statues is that burners must remain with the fire until it is completely extinguished (i.e., "dead out"). On one hand, the cost to a landowner (or the landowner's agent) for remaining an additional hour or day on a burn site is likely to be relatively low compared to the expected costs of an escape from an unattended smoldering fire. The crucial point here that leads to such a requirement is that without such a negligence standard, the costs of a burner leaving a site prematurely would likely be borne at least to some extent by a neighboring landowner rather than the burner. But this is yet another example of an incomplete contract in that specifying every indicator of "dead out" fires would be impossible. Moreover, the "dead out" requirement assumes low cost to the burner when in some cases, practicality in assessing "due care" in regard to attaining this standard would result in high cost to the burner. This is especially true on rangelands in which large burns, complex fuel involvement, rough topography, and other factors, limit the burner's ability to completely and accurately assess the fire's status. Moreover, the probability of fire escape may be very low. The specifics of the level of certainty of "safe-to-leave" decisions (i.e., mopping up including thorough "cold trailing") are not well defined in the rangeland fire literature and are beyond the scope of this paper.

Specific negligence rules for cost-effective inputs such as notification and on-site presence are consistent with implication 7 , because it is unlikely that the costs of such precautions will outweigh their expected benefits (i.e. reductions in expected damage). Even though limitations to their costeffectiveness exist, statutory specification of these rules will provide a higher degree of certainty about negligence requirements, thereby more effectively inducing proper precautionary incentives and reduce transaction costs of court proceedings.

The productivity and costs of many precautionary inputs, however, depend on the specific circumstances of a case. Attempts to impose a priori statutory requirements for input levels may lead to improperly specified negligence rules for many cases, and therefore should on efficiency grounds be left for a case-by-case analysis. Indeed, all statutory negligence standards for prescribed fire allow the courts the leeway to define "due care" (implication 7). Common elements considered by the courts in setting due care standards include starting fires during excessive dryness and foreseeable windiness, failure to build adequate firebreaks around the burn area, burning too close to neighboring property or buildings, and lack of sufficient accessible water (25ALR5th 391). The appropriate use of each of these inputs is relatively case dependent. Specification of statutory limits to be used in all cases would likely induce inappropriate precau- 
tionary levels in many cases. Specifying a complex set of statutory requirements based on a broad set of possible states of nature would arguably be more difficult (costly) than addressing these issues on a case by case basis.

An important characteristic of court negligence findings is that courts usually distinguish between foreseeable factors and abnormal or unforseeable factors contributing to the spread of fire, such as abnormal change in wind speed or direction. Our model suggests that the probability of the fire spreading to neighboring lands should be considered when establishing negligence. This probability is in turn based in part on expectations about exogenous factors such as wind. When deciding whether a burner started a fire negligently, courts generally base their decisions on the information that was available to burners at the time the fire was started. A burner may be found negligent if prevailing winds were unsatisfactory when the fire was ignited, but generally would not be found negligent for the spread of fire resulting from an abnormal and unforeseen change in the wind patterns (25 ALR5th 391).

\section{Permits and regulatory require- ments}

Regulatory restrictions and permits are property rules providing landowners with the right to burn only if they satisfy a set of requirements delineated by statute and regulatory agencies. Otherwise, the burner may be subject to criminal penalties. These are different from liability rules, where burners have the right to perform prescribed burns but must bear the liability associated with the burn. As is the case with many environmental issues, a priori regulation and ex post liability are used simultaneously in many states to address prescribed fire externalities.

Property rules for prescribed burning are imposed for 2 general types of activities: for burning without a permit or contrary to permit stipulations, and for leaving a fire unattended or for negligent escape and failure to extinguish. Most states maintain a permit system for prescribed burning under some circumstances. In some states, satisfaction of permit requirements is necessary to avoid potential fines and other criminal penalties. To acquire a permit, the landowner may have to show sufficient knowledge, preparation, and notification of neighbors or public fire-fighting entities. Colorado's statute, for example, states that permits are to be issued based on the proximity of the planned burn to buildings, the potential contribution of the fire to air pollution, climatic conditions, and other related factors. These requirements, when used in conjunction with a negligence rule, are consistent with implication 5. Pre-fire acquisition of a permit is necessary to be eligible for public firesuppression support in some states, and the acquisition of a permit is an element of a negligence rule in some states as well.

\section{A new generation of prescribed fire statutes}

A new generation of prescribed fire statutes have been developed in the southeastern states beginning with Florida in 1990 (Brenner and Wade 1992). The Florida statute goes to great length to recognize prescribed burning as a useful land management tool. The legislation explicitly recognizes ecological benefits, and benefits from reducing the likelihood and severity of wildfires. It explicitly recognizes prescribed burning as a property right, subject to a relatively detailed set of precautionary requirements. Finally, it specifies that landowners are not liable for damage or injury caused by escaped fire or smoke unless found to be grossly negligent. Other southern states to explicitly recognize prescribed burning as a beneficial property right include Georgia, Louisiana, Mississippi, and North Carolina. In the context of our model, the explicit recognition of the value of prescribed burning acts to emphasize the possibility that $\mathrm{R}^{1}$ in Figure 1 is high, arguably increasing the likelihood that a value-based rule is found by the courts to be satisfied. The requirement of gross negligence arguably lowers the negligence standard, $\overrightarrow{\mathrm{B}}$, relative to not requiring gross negligence. These statutes are therefore consistent with an apparent attempt to reduce the likelihood of prescribed burner liability.

If land and demographic characteristics of southern states result in relatively large benefits from prescribed fire, our model predicts more widespread use of negligence rules in these states (implication 5). One conjecture regarding the relative support of prescribed burning in these new statutes is that these statutes are a response to an apparent growing recognition of the role of prescribed fire as a wildfire management tool.

To the extent that reduction of fuel loads resulting from controlled burning reduces the likelihood and severity of wildfires, prescribed burners may contribute positive externalities by reducing potential fuel accumulation that would contribute to fire spread across numerous landholdings in a region. If this conjecture is correct, we would expect this type of statutory response in areas where prescribed burning can reduce the total social costs of fire generally (that is, the net cost of prescribed fires plus the costs of wildfires and their control).

\section{Conclusions}

Prescribed fire is a land management tool with long historical roots in rangelands of North America, Australia, and elsewhere. A resurgence in interest from scientists, land managers, and legislators has led to substantial changes in the statutory law of many states in recent years. This paper examines the economics of liability for prescribed fire. Using a graphical representation of a mathematical model developed in Yoder et al. (2003), we provide a conceptual framework for improving existing policy at a time when prescribed burning policy is in a state of flux.

The risk of fire escaping to neighboring landholdings always accompanies the use of prescribed fire, and burners therefore may not bear all of the potential costs of their prescribed burning decisions. Criminal and civil liability rules specified by legislation and enforced by the courts work to internalize these costs. The relative effectiveness of a liability rule depends in large part on the relative ability of burners and other landowners to mitigate the probability and extent of damage, as well as the transaction costs associated with implementing a given liability rule.

All negligence rules rely on an ambiguous requirement of due care that is left to be defined more specifically by the courts, but many states include specific negligence standards as well. Most of the recent changes in statutory law relating to prescribed fire provide substantial support for prescribed fire as a land management tool despite the risks associated with its use. These changes may result more from the increasing evidence that prescribed fire can be a cost-effective means of reducing the incidence and intensity of wildfires.

This paper is about tradeoffs in the design of law. State prescribed fire law varies across states, and these laws affect the amount of precautionary effort expended by burners and their neighbors. Strict liability induces appropriate precaution from the person conducting the burn if a prescribed fire is performed, but neighbors have little incentive to reduce potential damage. Negligence standards, if 
properly set, induce appropriate precaution by both burners and neighbors for any prescribed fire, but prescribed fires may be performed too often from an economic perspective. Strict liability is likely to result in fewer escaped prescribed fires than a properly set negligence rule, but this comes at a cost as well, including excessive precaution costs by the burner, potentially higher damage for any escaped fire, and less aggregate benefits from fires because fewer prescribed fires will be performed. If one of the objectives of liability law in this context is to promote total social welfare and economically efficient resource management, these tradeoffs must be addressed when tailoring law to a given environment.

\section{Literature Cited}

American Law Reports Editorial Staff $\left(25\right.$ ALR5 $\left.^{\text {th }} 391\right) 1994$. Liability for spread of fire, intentionally set for legitimate purposes. American Law Reports 25:391-567.

Babbitt, B. 1995. To take up the torch. Amer. Forest. 101:7-8.

Bernardo, D., D. Engle, and F.McCollum. 1988. An economic assessment of risk and returns from prescribed burning on tallgrass prairie. J. Range Manage. 41:178-183.
Biswell, H. H. 1989. Prescribed burning in California wildlands vegetation management. Univ. of Calif. Press. Berkeley Calif.

Brenner, J. and D. Wade. 1992. Florida's 1990 Prescribed Burning Act: Protection for responsible burners. J. For. 90:27-30.

Briggs, J. and A. Knapp. 1995. Interannual variability in primary production in tallgrass prairie: Climate, soil moisture, topographic position, and fire as determinants of aboveground biomass. Amer. J. Bot. 82:1024-1030.

Brown, J. 1973. Toward an economic theory of liability." J. Legal Studies 2:323-349.

Chalifour, N. 1999. Legal considerations, p. 18 of Section IIIB. In: Fire in Ecosystem Management. Tucson, Ariz., March 23-April 1. National Advanced Resource Technology Center, Tucson, Ariz.

Coase, R. H. 1960. The problem of social cost. J. Law and Econ. 3:1-44.

Cooter, R. D. 1991. Economic theories of legal liability. J. Econ. Perspectives 5:11-30.

Cooter, R. and T. Ulen. 1988. Law and economics. Harper Collins. New York, N.Y.

Engle, D.M. and T.G. Bidwell. 2001.. Viewpoint: The response of Central North American prairies to seasonal fire. J. Range Manage. 54:2-10.

Feldman, A. M. and J. M. Frost. 1998. A simple model of efficient tort liability rules. Int. Rev. Law and Econ. 18:201-215.

Interagency Burned Area Emergency Rehabilitation Team. 2000. Cerro Grande Fire Burned Area Emergency Rehabilitation Plan. Tech. Rep. http://www.baerteam.org/cerrogrande/Rehabilitation Plan.pdf (22 Jan. 2002).
Kolstad, C. D., T. S. Ulen, and G. V. Johnson. 1990. Ex post liability for harm vs. ex ante safety regulation: substitutes or complements? Amer. Econ. Rev. 80:888-901.

Pattison, M. 1998. Fighting fire with fire: A policy to improve resource management and reduce risk. Renewable Resources J. Summer:13-17.

Pyne, S. J. 1982. Fire in America: A cultural history of wildland and rural fire. Princeton University Press. Princeton, N.J.

Roberts, K.W., D.M. Engle, and J.R. Weir. 1999. Weather constraints to scheduling prescribed burns. Rangelands 21:6-7.

Svejcar, T. 1989. Animal performance and diet quality as influenced by burning on tallgrass prairie. J. Range Manage. 42:11-15.

Tietenberg, Tom. 2000. Environmental and natural resource economics. $5^{\text {th }}$ ed. Addison Wesley Longman, Inc. Reading.

U.S. Department of the Interior, U.S. Department of Agriculture. 1995. Federal wildland fire management policy and program review, final report. Tech. Rep. http://www.fs.fed.us/land/wdfire.htm. (22 Jan. 2002).

Yoder, J., M. Tilley, D. Engle, and S. Fuhlendorf. 2003. Economics and prescribed fire law in the United States. Rev. Agr. Econ. 25:218-233.

Zimmerman, J. 1997. Avian community responses to fire, grazing, and drought in the tallgrass prairie. pp. 167-180, In: F. Knopf and F. Samson (eds.), Ecology and conservation of Great Plains vertebrates. Springer. New York, N.Y. 